\title{
The Acts and Decrees of the Synod of Diamper and the Machinations of Religious Colonization
}

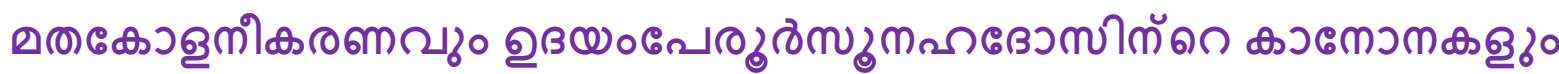

\author{
Shimi Paul Baby a, *
}

a Department of Malayalam, Union Christian College, Aluva-683102, Kerala, India.

*Corresponding author Email: shimipaul2@gmail.com

DOI: https://doi.orq/10.54392/ijmrd2147

Received: 09-11-2021; Revised: 21-12-2021; Accepted: 25-12-2021; Published 27-12-2021

\begin{abstract}
The Synod of Diamper is, arguably, amongst the most significant milestones in the history of St. Thomas Christians in Kerala. This Synod was convened in the church at Udayamperoor, Kochi, Kerala, from June 20 to June 26, 1599. As is documented, it was Archbishop Alexis De Menezes of Goa who convoked this Synod. 200 decrees were passed during the nine sessions which were held during the Synod; these decrees, in toto, became a turning point in the history of Christianity in Kerala. Primarily, the Synod of Diamper was a religious/theological one. However, its subsequent decisive role in the history and culture of Kerala also gave the Synod a social face. A close scrutiny of the canonas [canon] reveals that these decrees were formulated with a consideration of only Christian practices that were prevalent and familiar in the West [Occident]. In a grimly ironic sense, the canonas overtly attempts a coax-hoax, whereby the Christians of Kerala would be coerced to follow the rules of the occidental version of Christianity; and this disciplining would be aided by various methods including expulsions from parish, ex-communication, etc. One big fallout of this scenario was that the Christians of Kerala, who till then had a variegated co- existence with different cultures, were forced to take up an exclusive and singular notion of Christian culture. Through these canonas, many of the existing socio- cultural customs of the Christians of Kerala were abolished; an attempt to sculpt the socio-cultural life of this native populace and bring it in accordance with the image of the Christian that the West upheld. This article aims to reveal the methodology through which the Institutionalized Western Theological-agencies, by means of constant surveillance and an enforced seclusion-exclusion axis, exerted power on regional and native Christian group.
\end{abstract}

Keywords: Colonialism, Religious Colonization, Synod of Diamper, Postcolonialism, Orientalism, Kerala Christians, Surveillance

\section{Subject Specialization: Malayalam}

\section{About the Author}

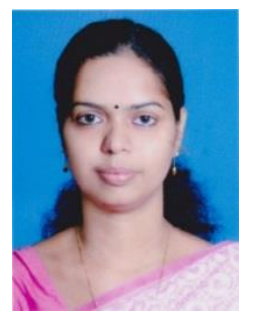

Dr. Shimi Paul Baby, working as an Assistant Professor in the Department of Malayalam, Union Christian College, Aluva, Ernakulam, a district of Kerala. She had published 14 research papers, authored and edited books in Malayalam Language and Literature.

बோவுவ०

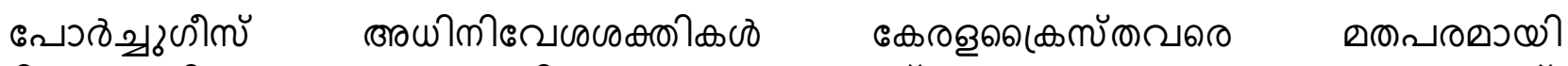

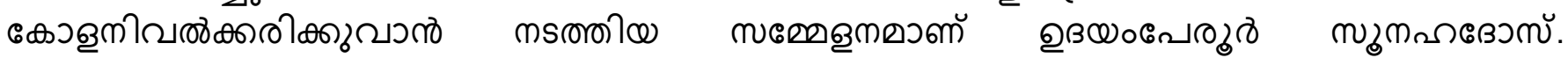

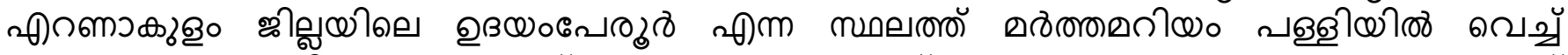

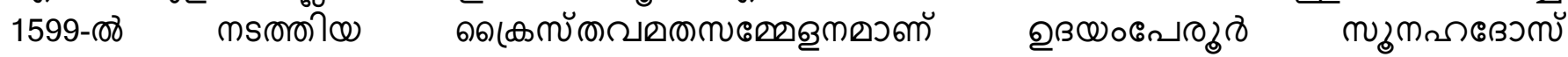




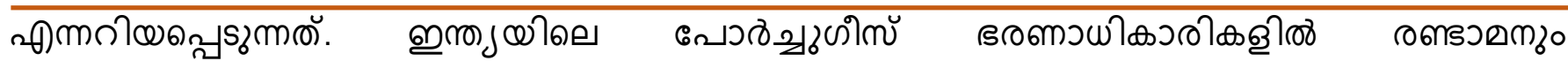

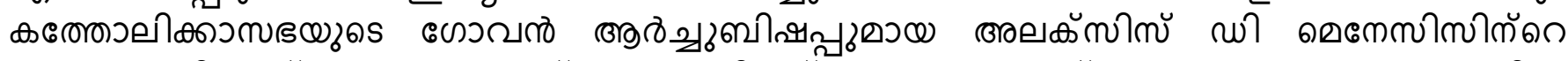

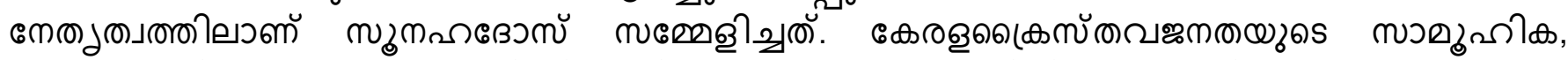

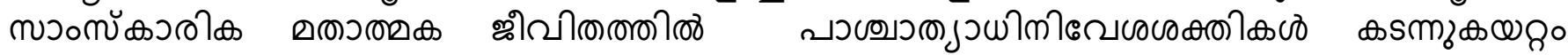

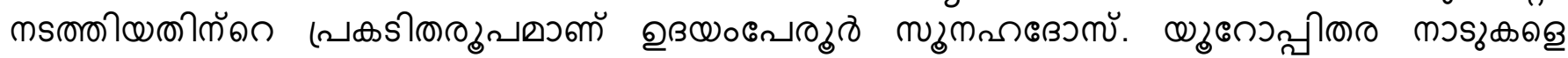

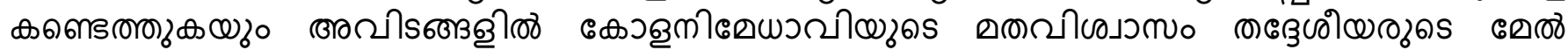

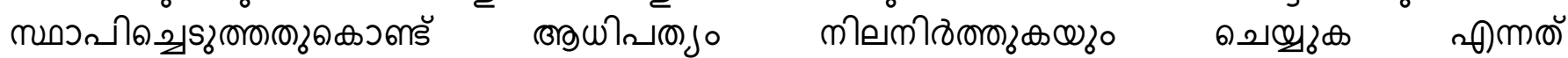

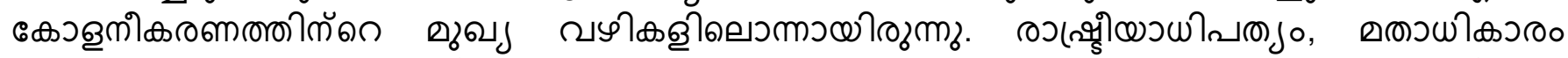

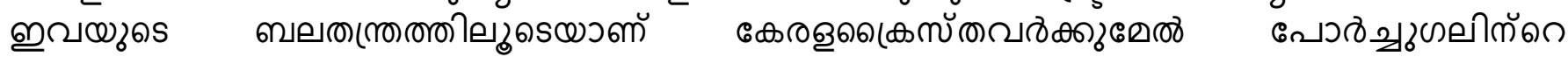

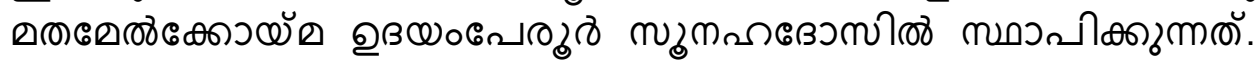

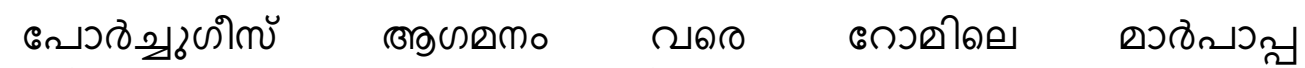

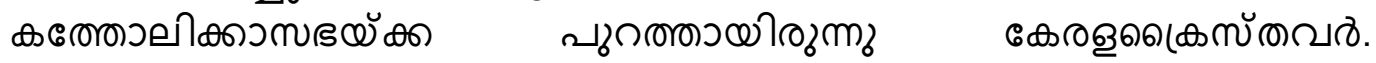

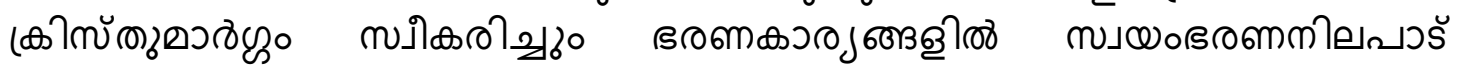

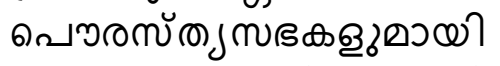

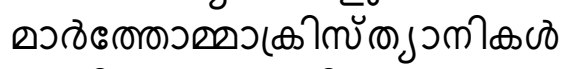

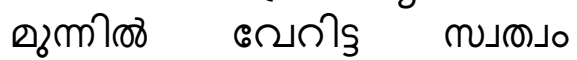

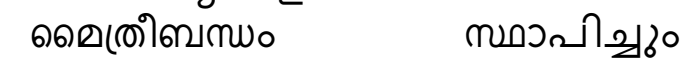

लைவாวक्ठญญ

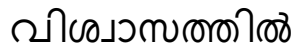

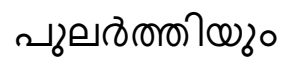

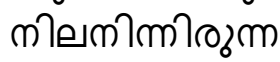

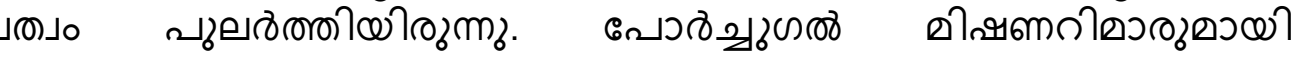

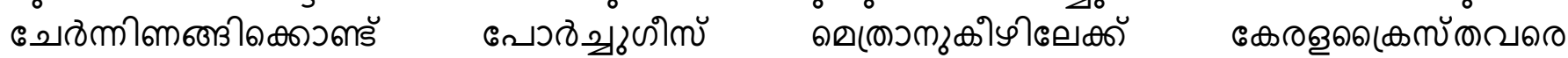

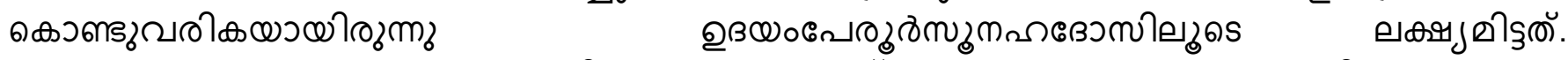

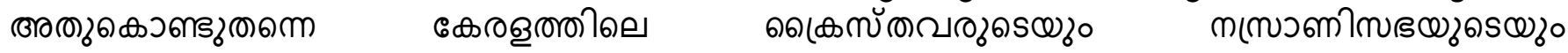

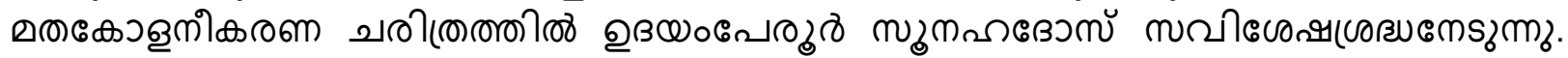

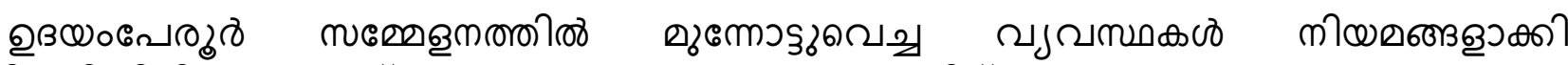

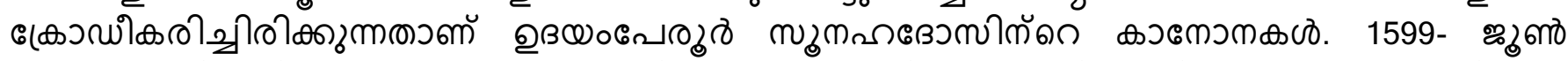

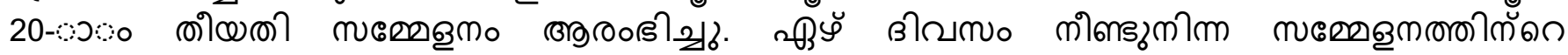

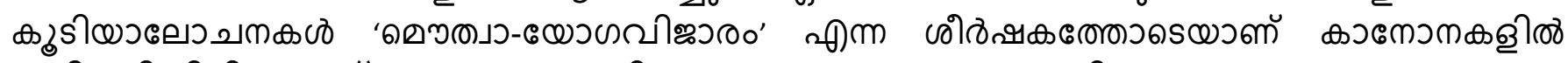

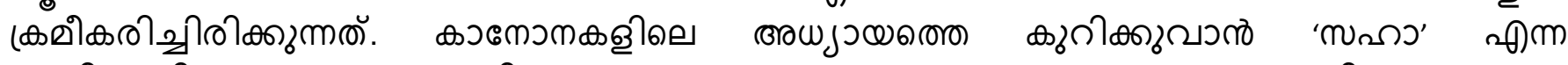

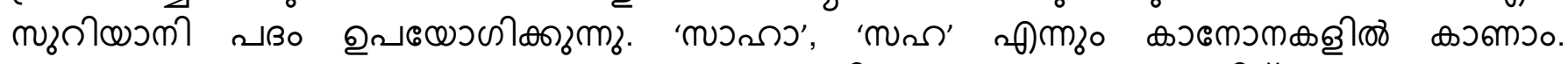

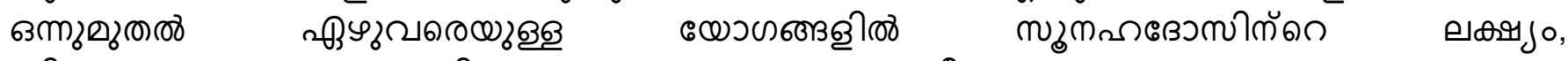

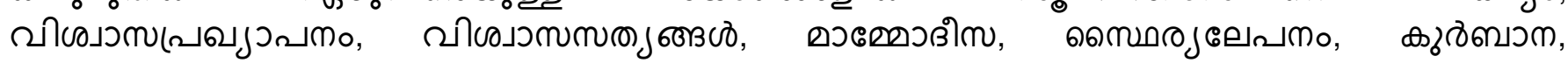

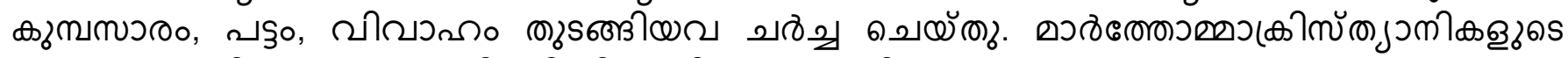

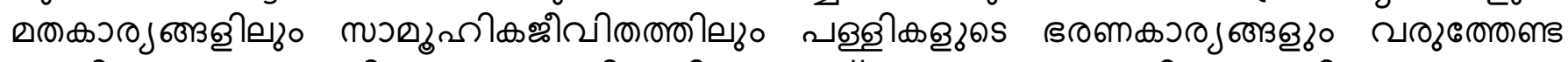

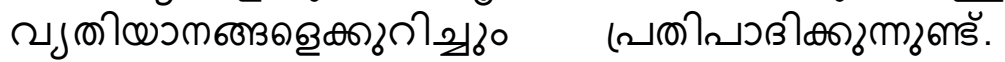

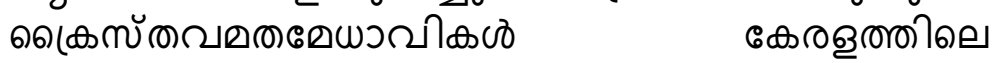

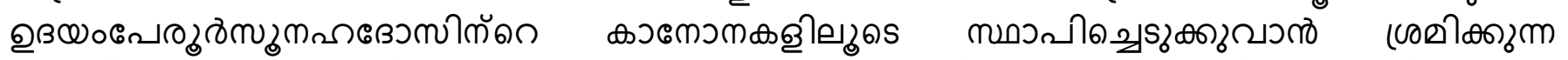

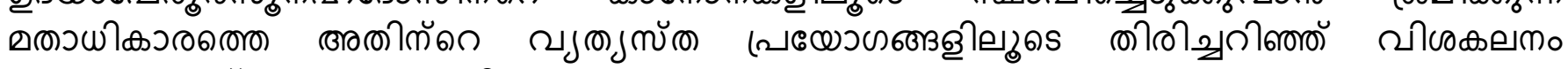

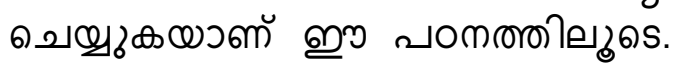

\section{(ே)}

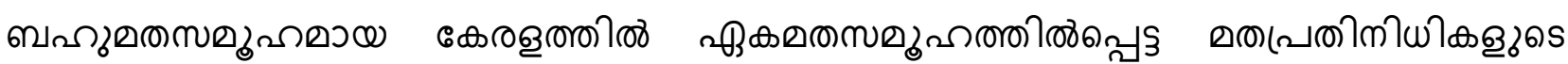

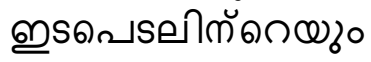

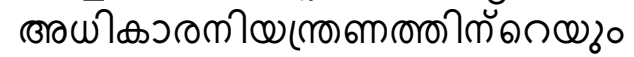

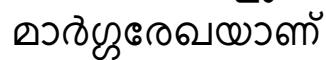

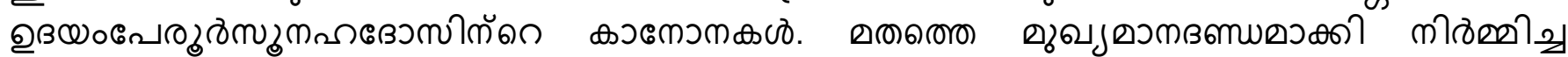

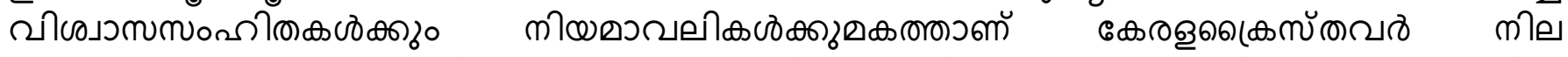

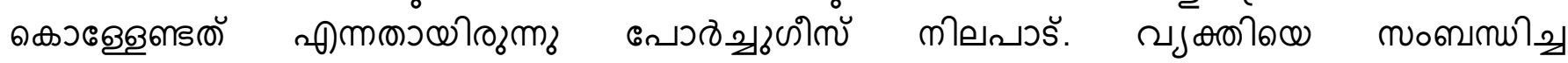

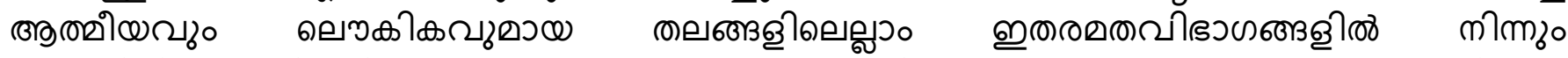

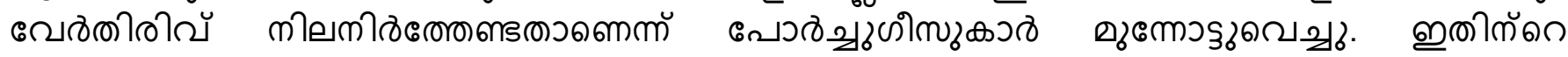

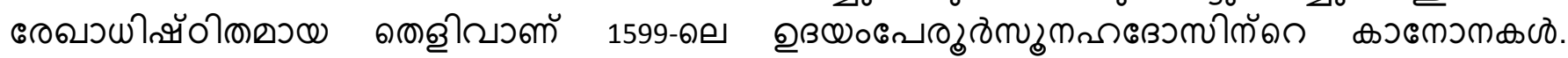

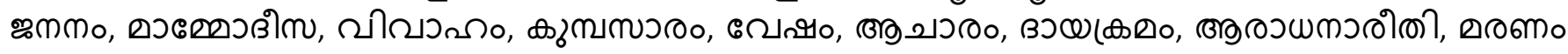




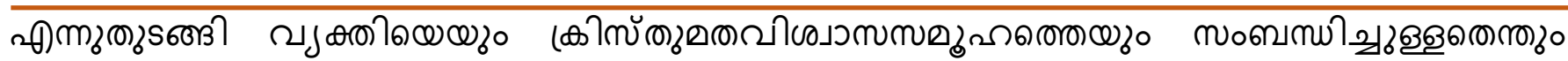

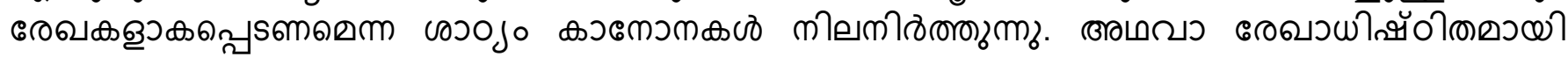

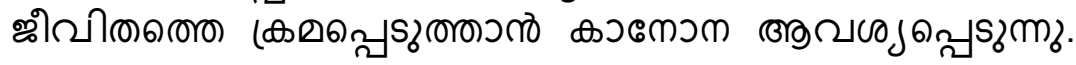

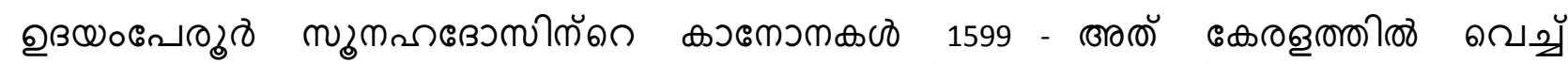

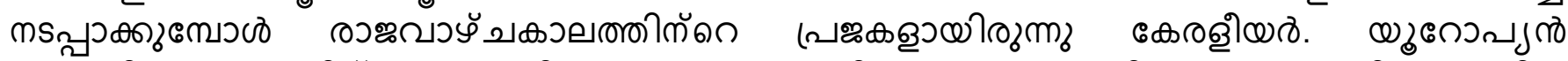

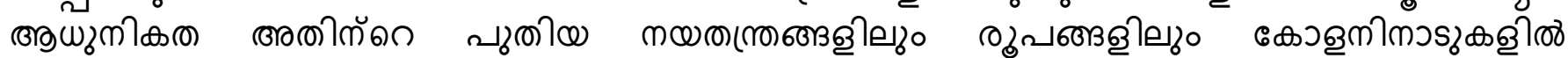

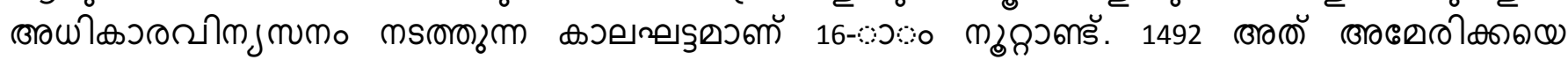

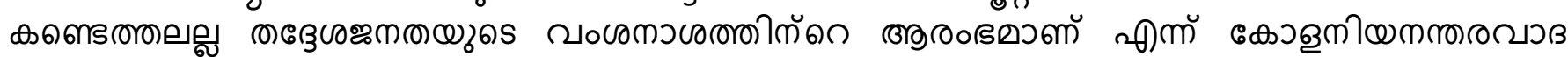

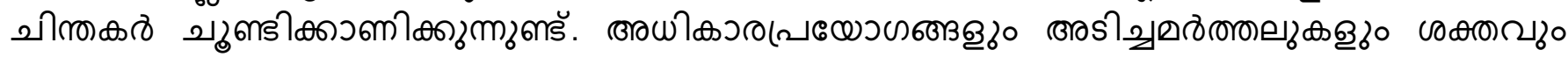

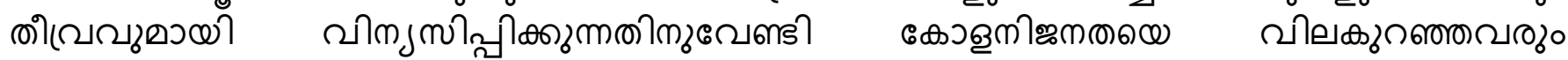

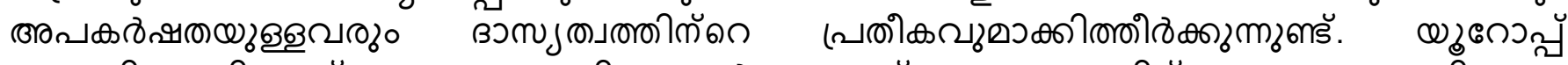

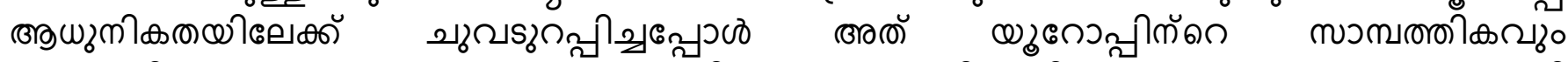

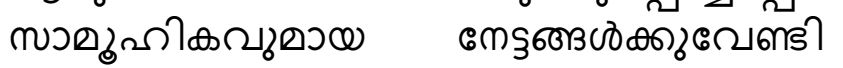

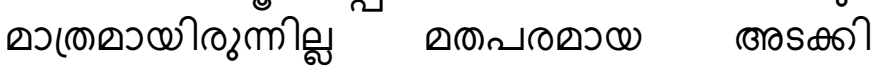

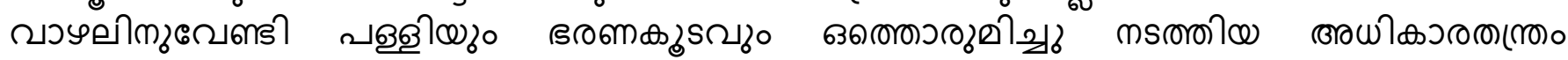

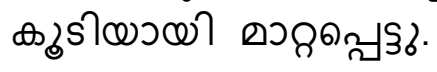

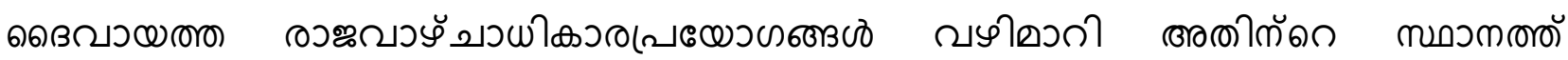

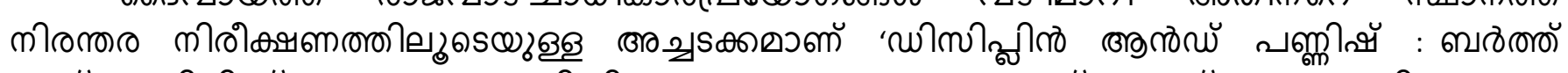

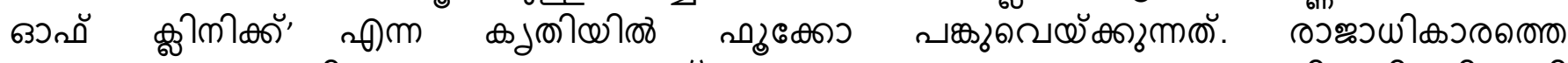

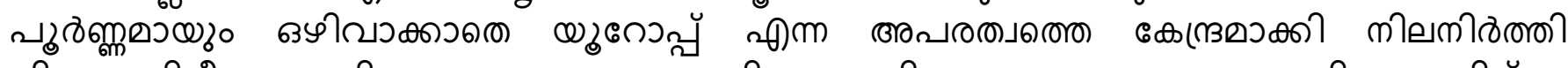

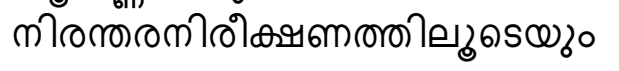

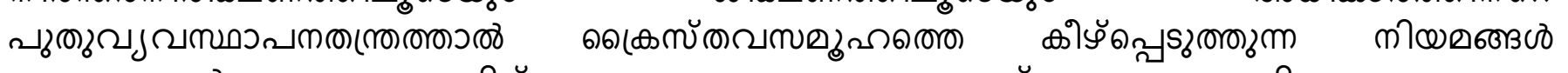

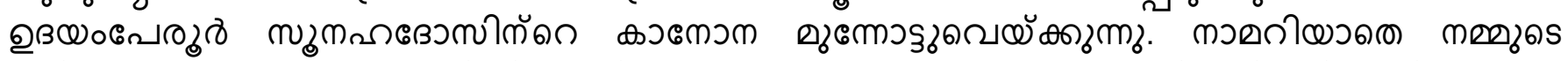

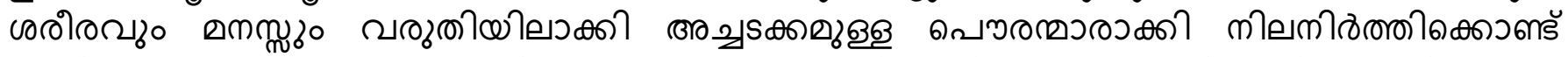

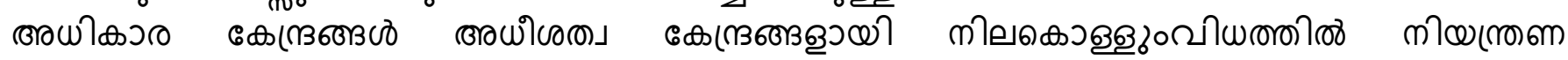

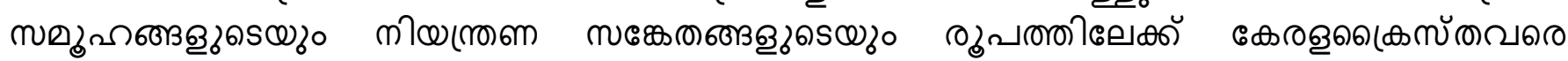

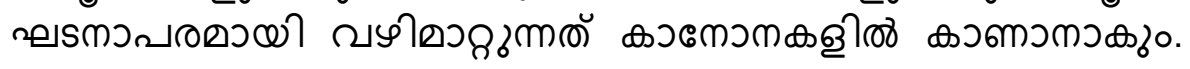

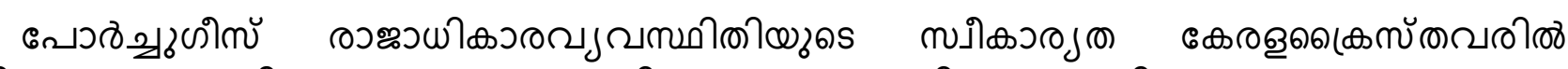

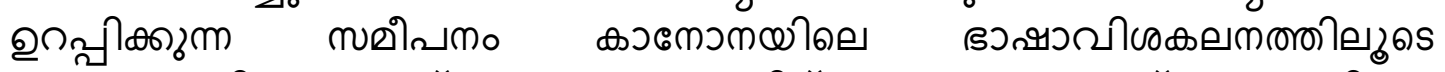

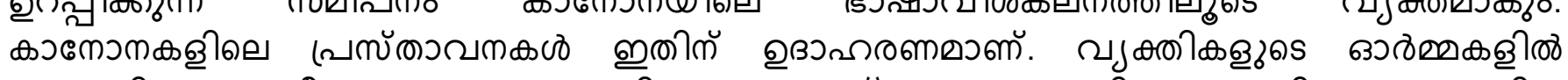

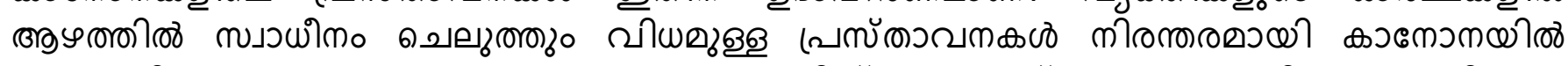

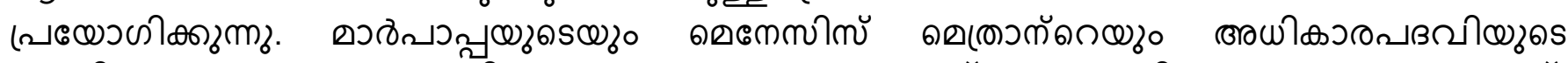

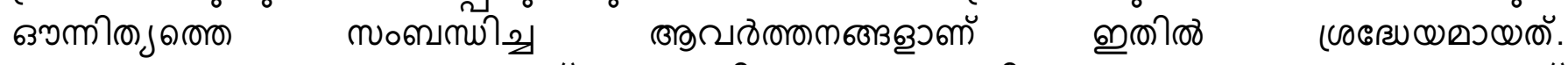

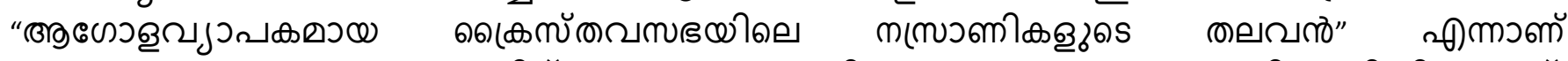

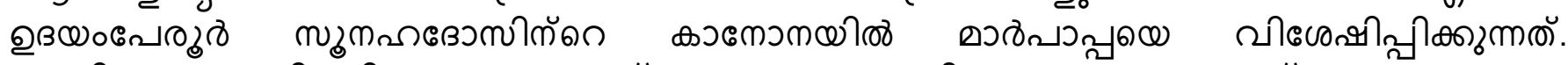

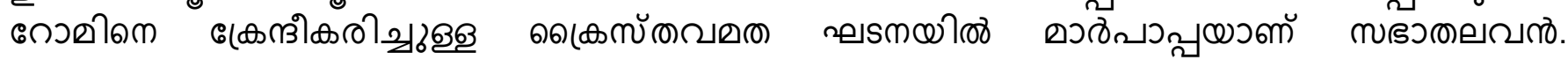

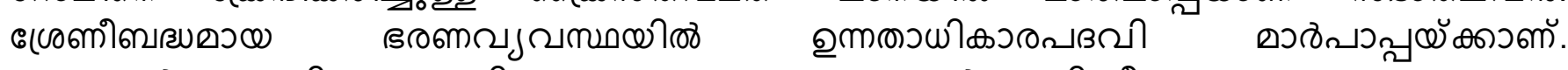

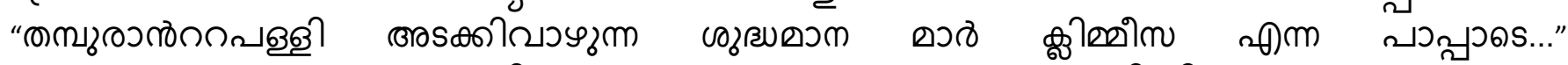

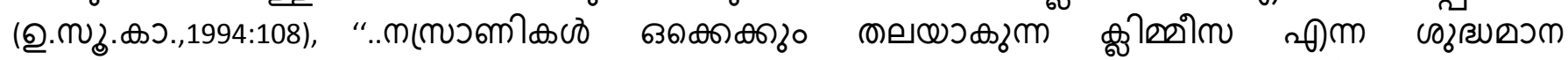

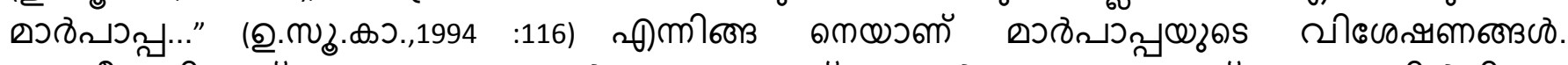

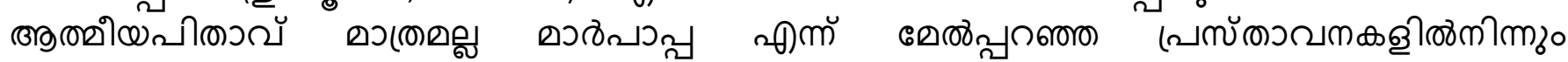

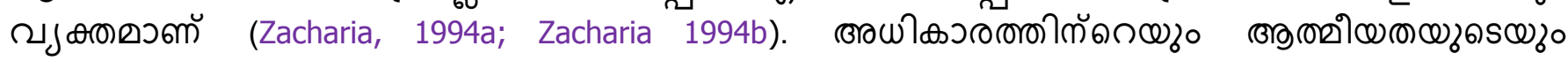

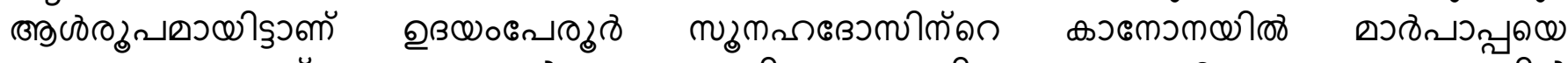

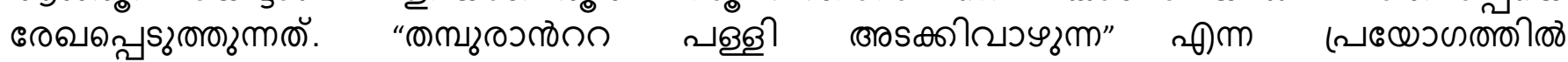

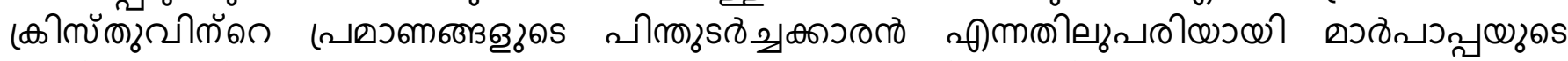

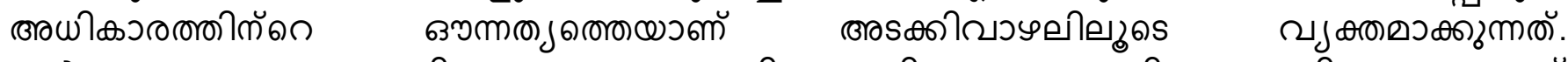

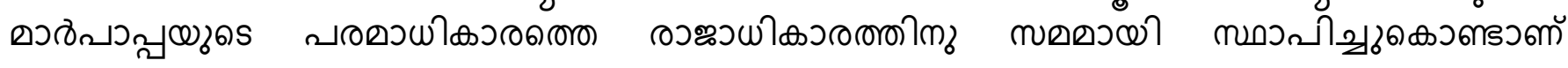




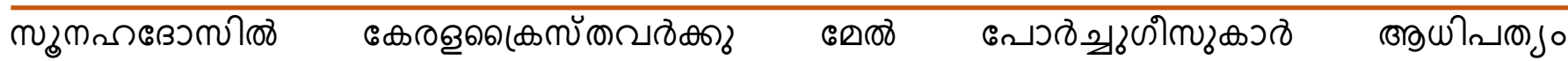

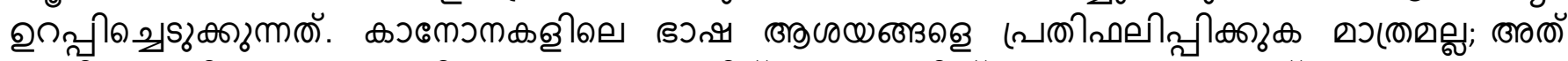

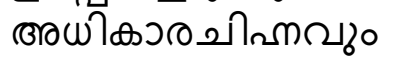

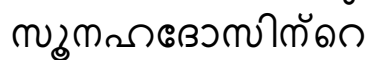

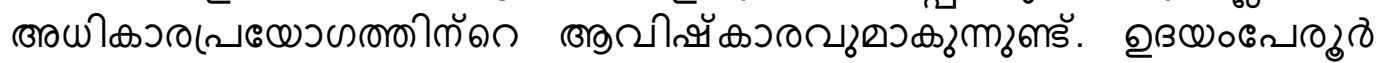

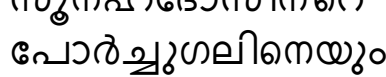
कวกேวாமาช ஹऽெSுm

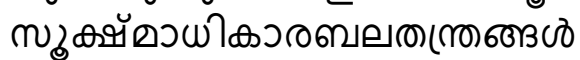

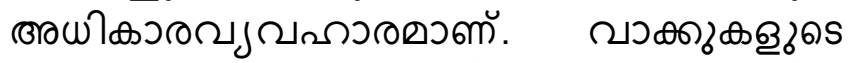

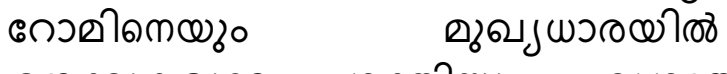

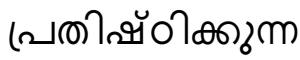

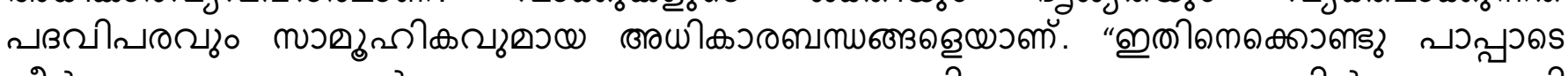

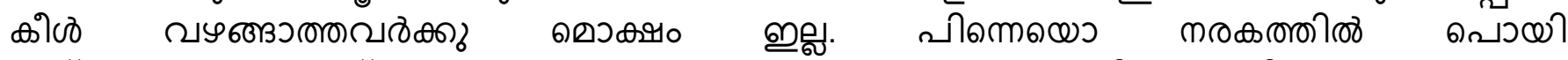

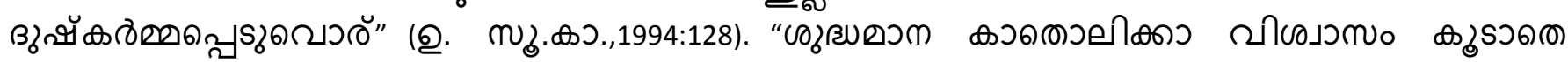

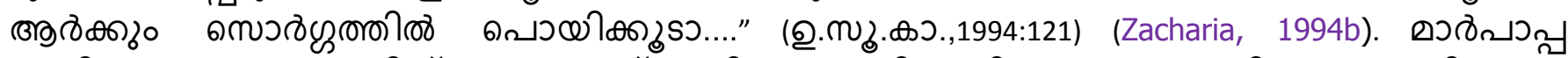

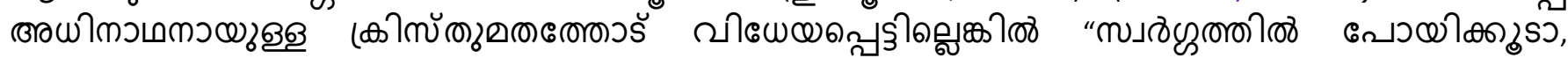

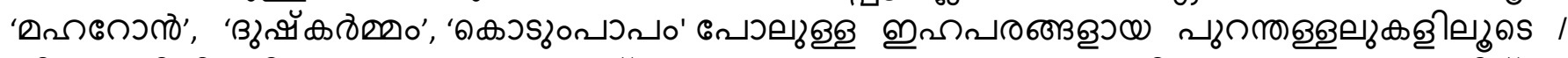

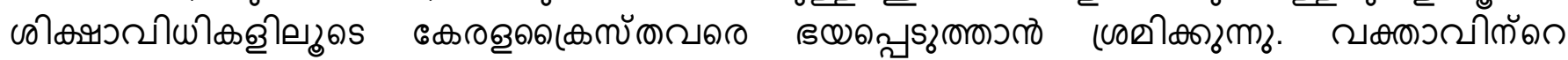

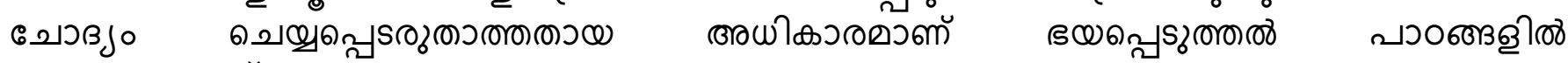

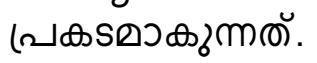

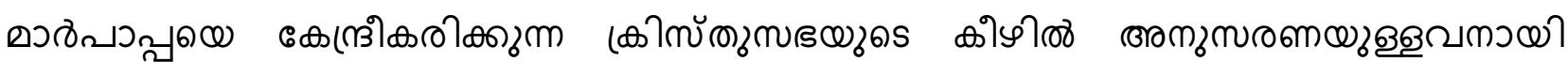

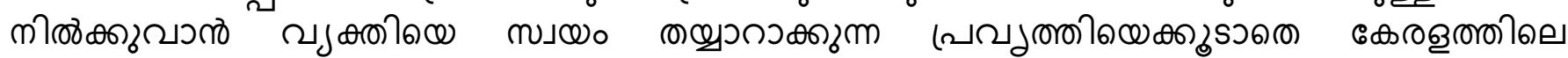

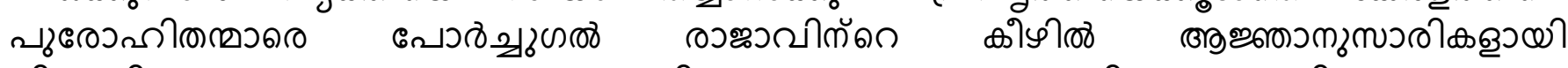

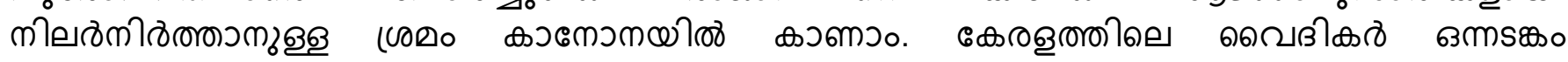

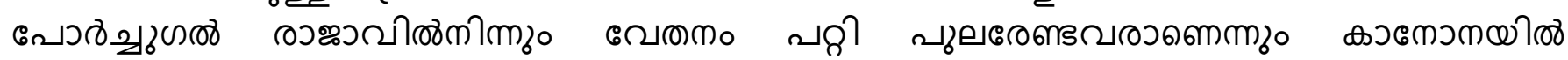

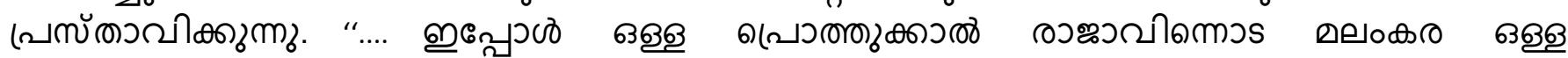

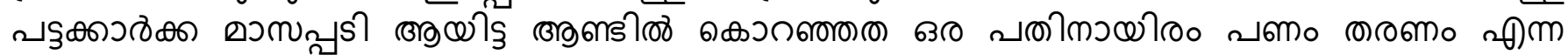

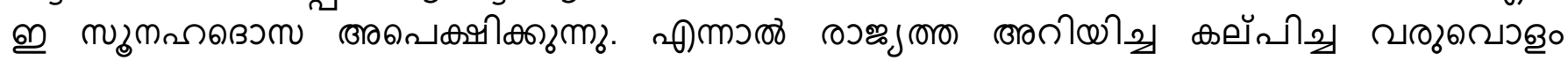

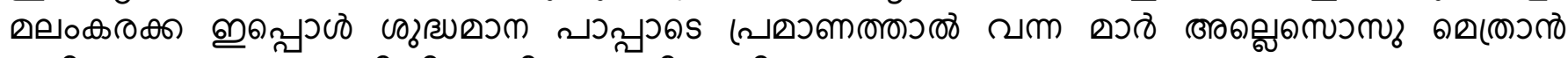

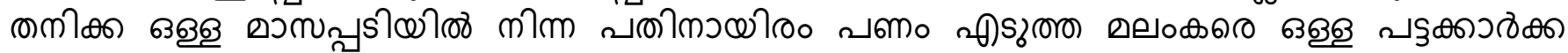

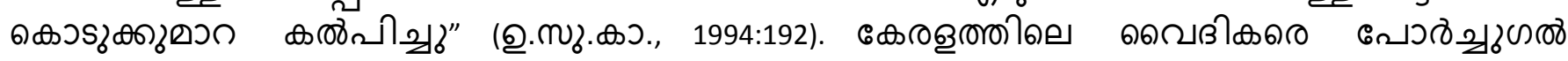

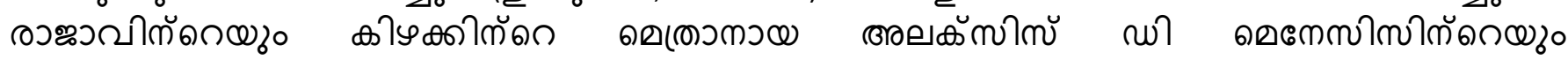

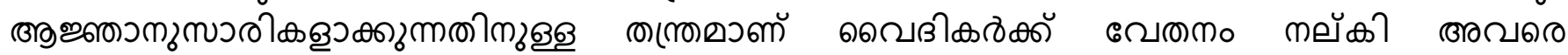

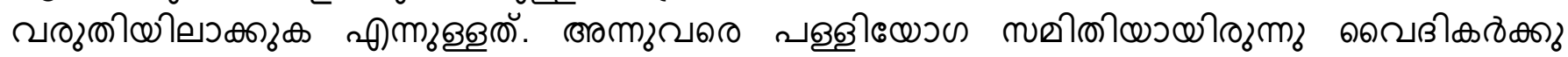

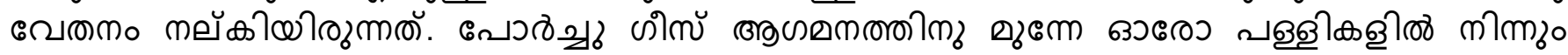

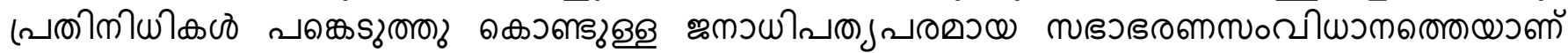

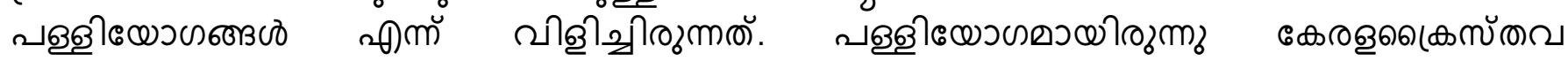

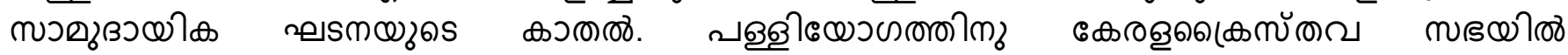

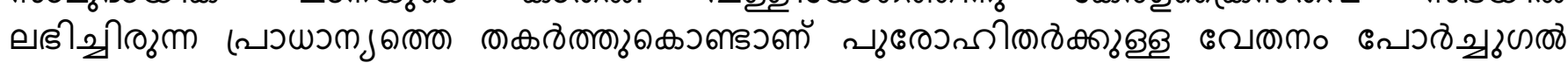

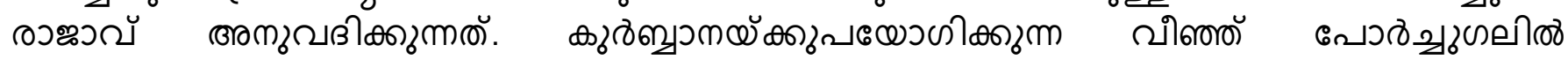

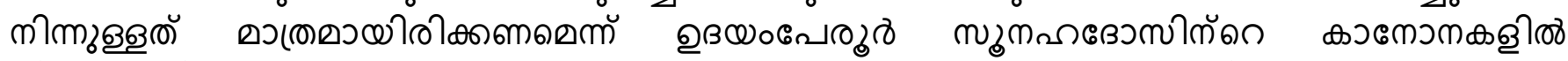

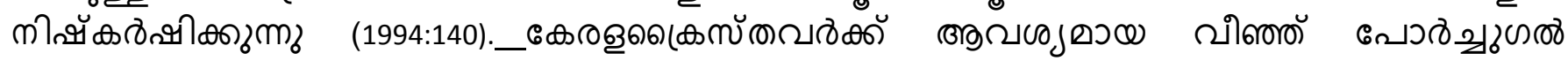

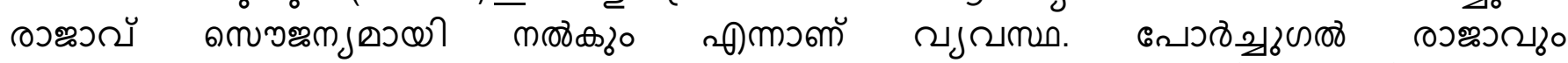

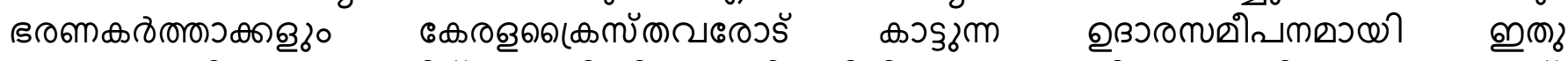

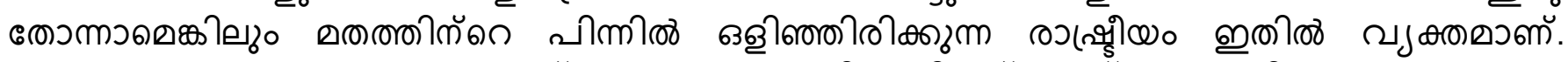

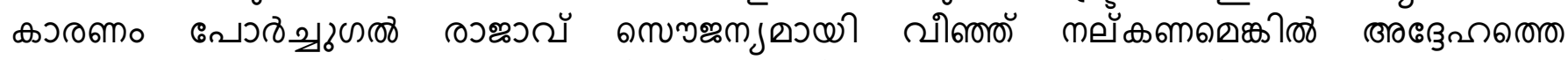

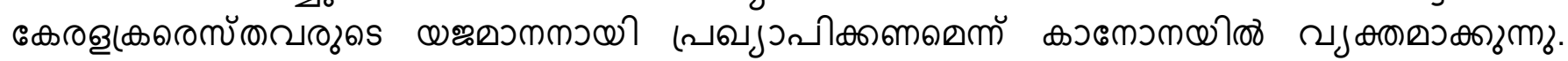
வीकाృ வ

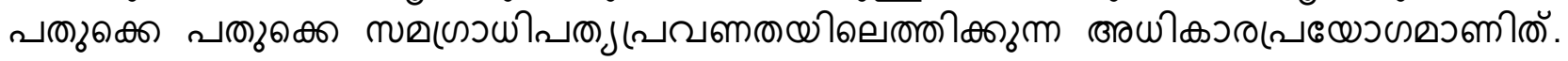

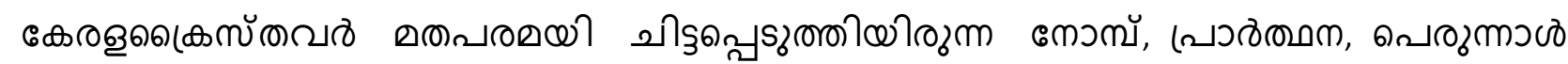

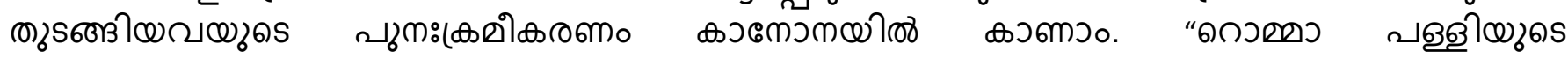

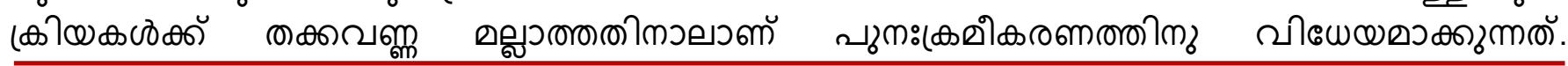




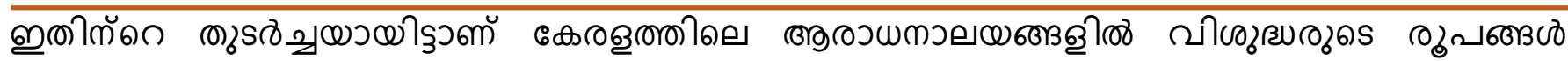

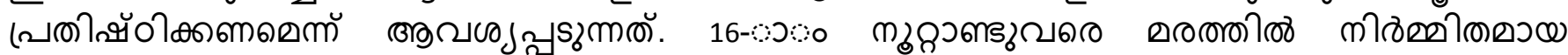

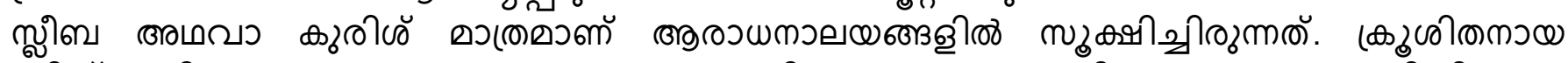

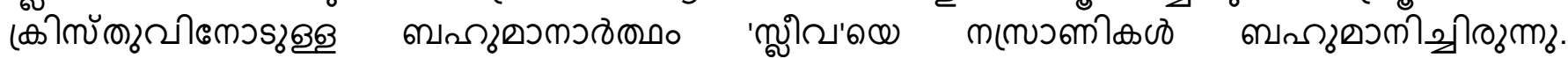

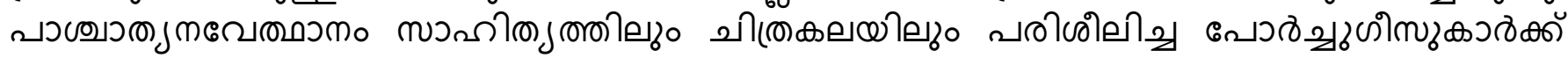

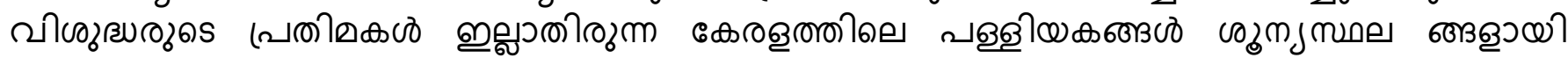

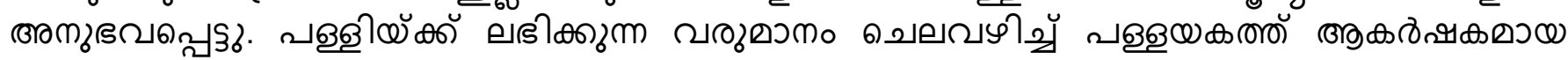

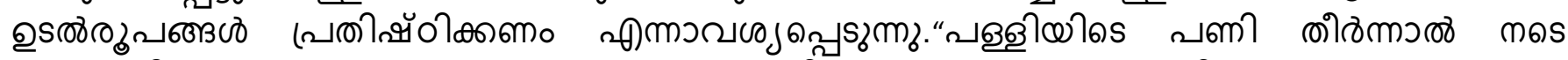

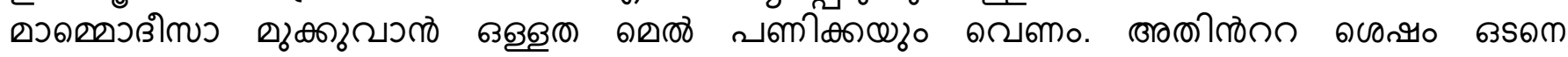

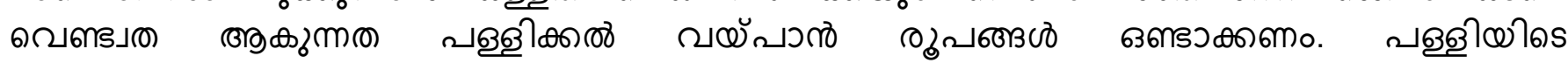

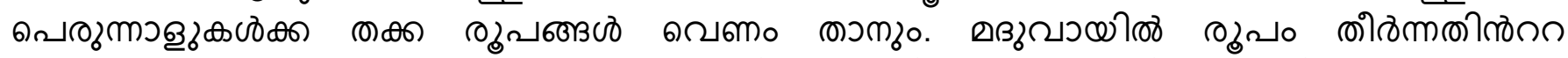

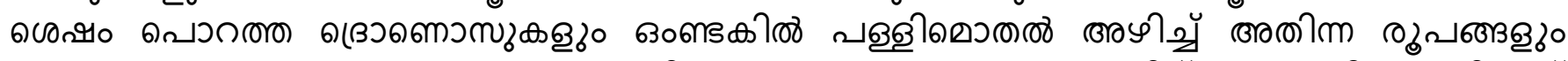

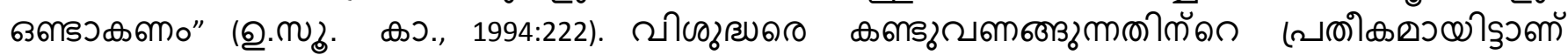

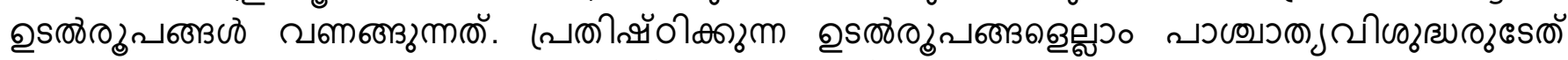

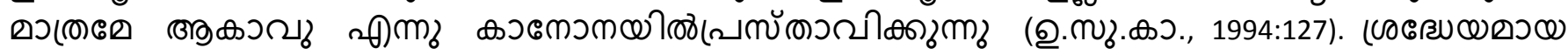

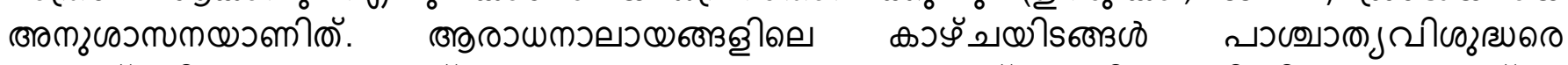

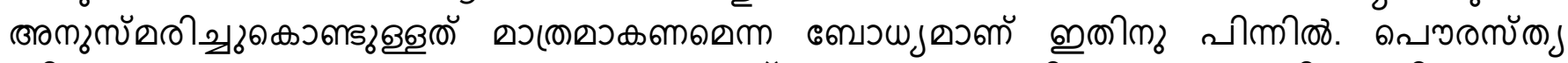

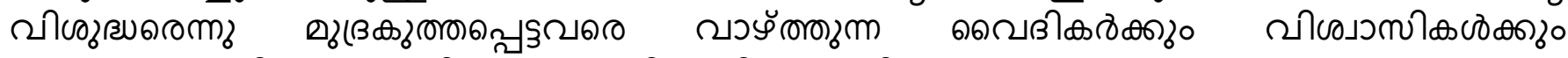

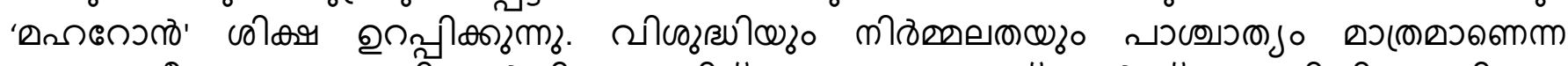

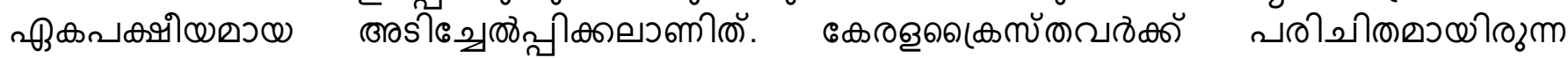

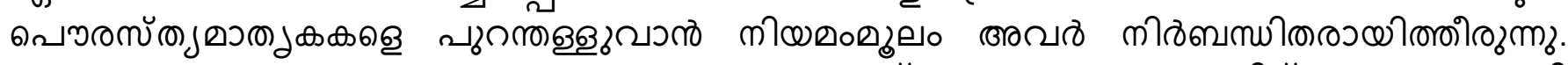

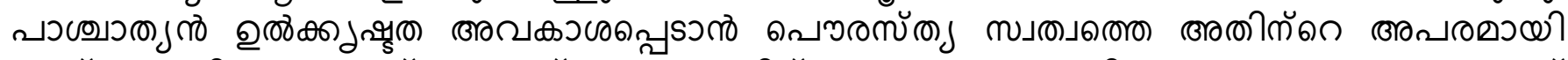

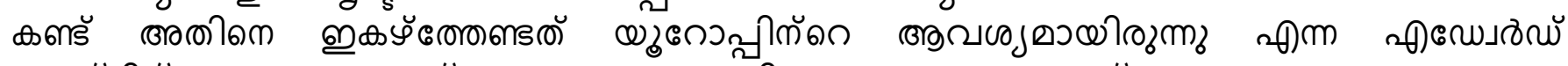

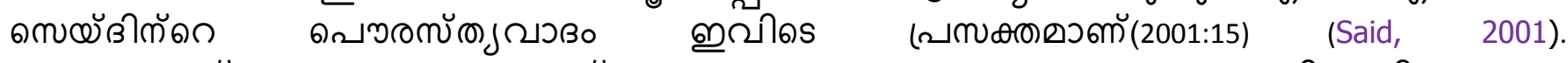

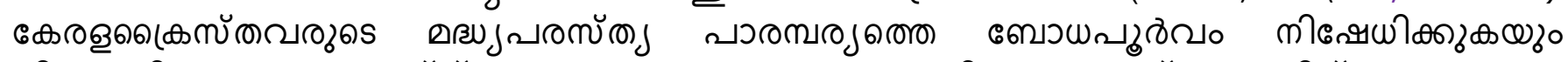

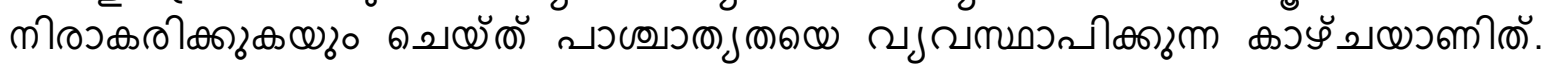

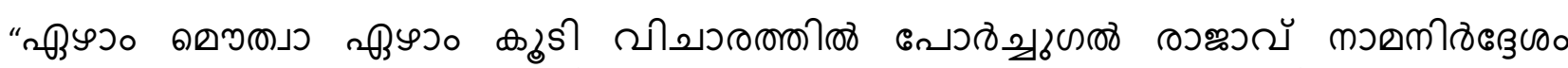

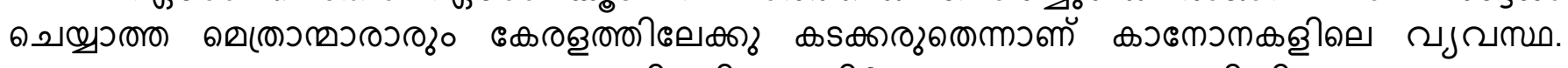

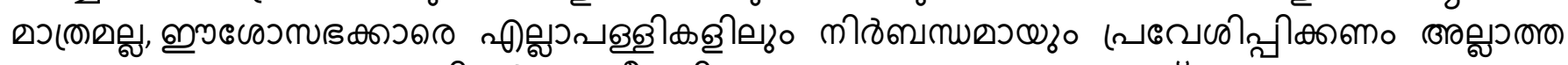

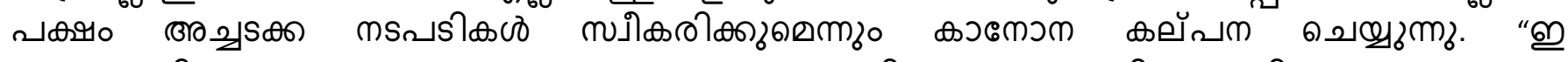

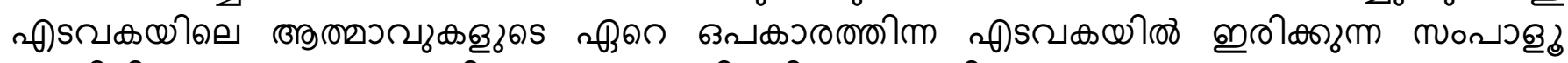

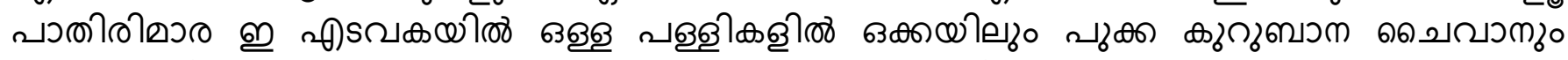

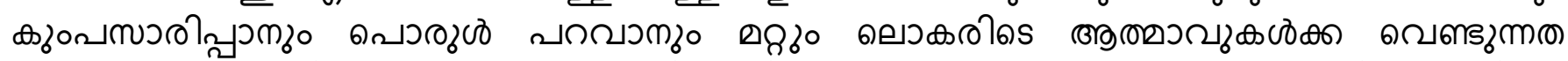

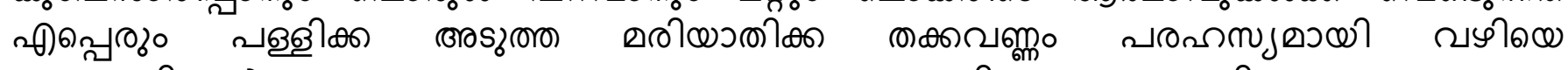

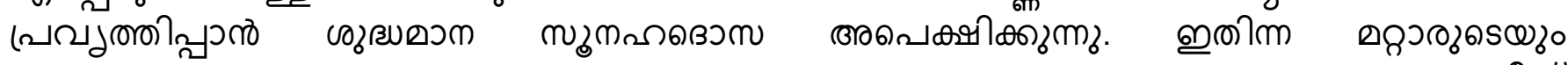

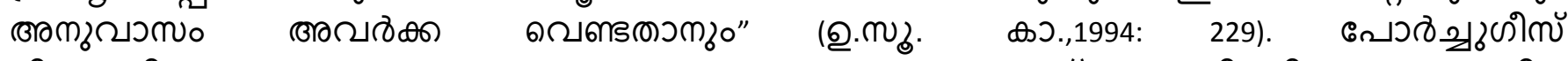

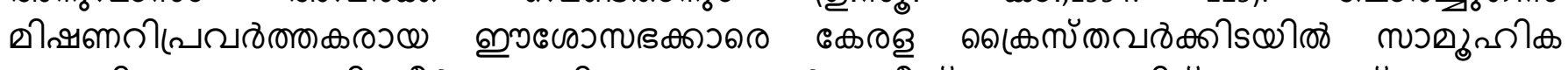

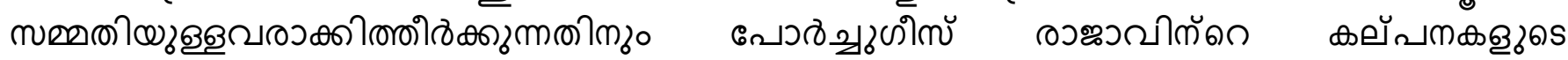

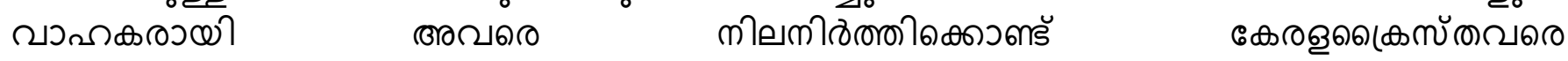

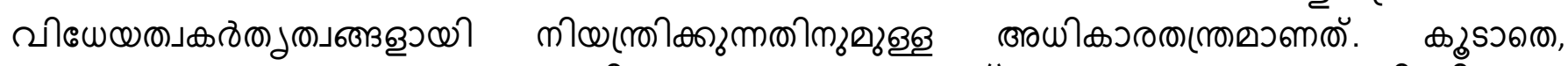

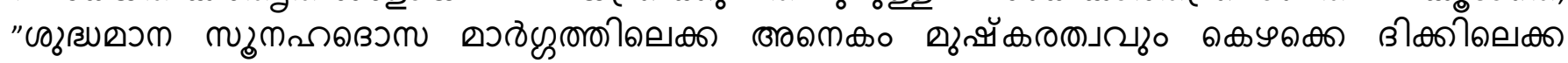

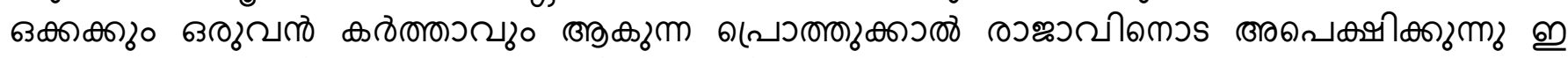

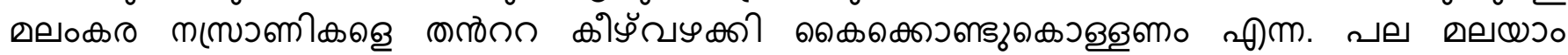

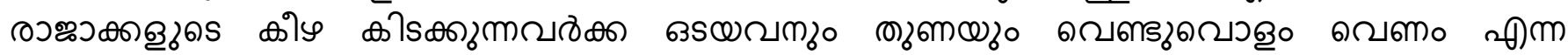

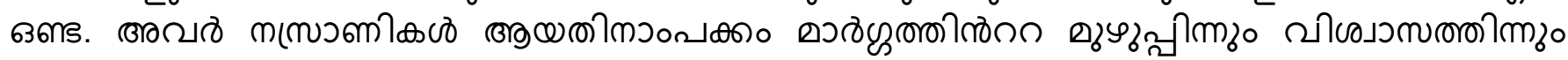

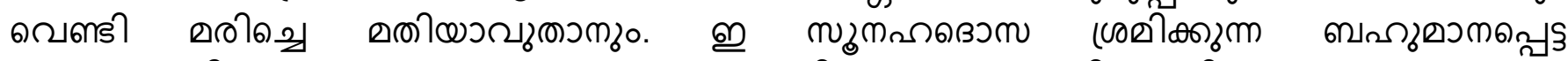

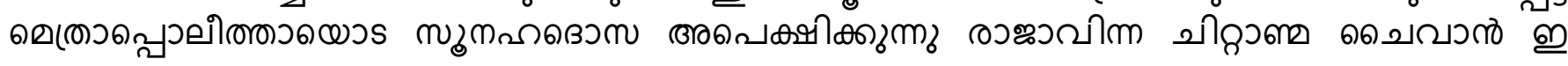




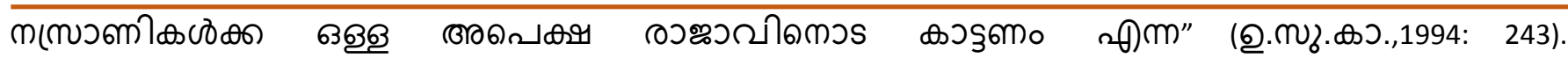

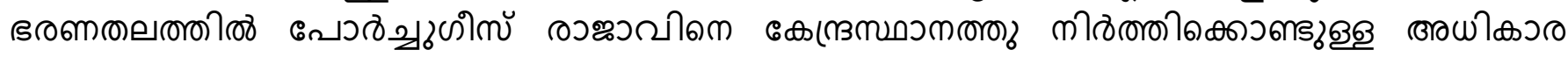

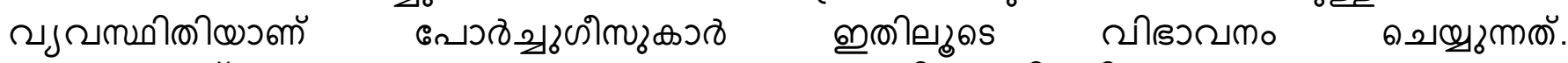

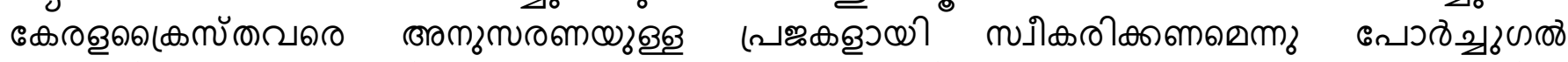

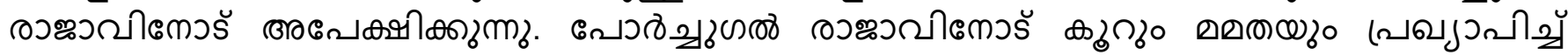

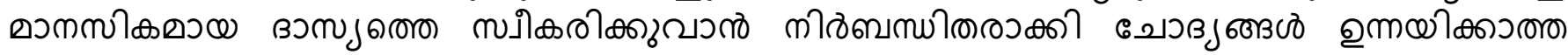

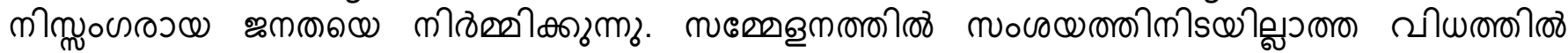

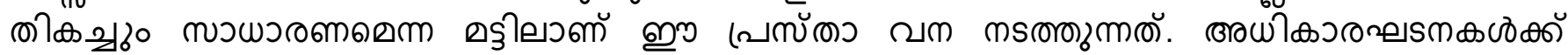

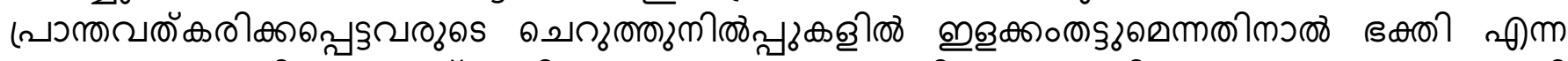

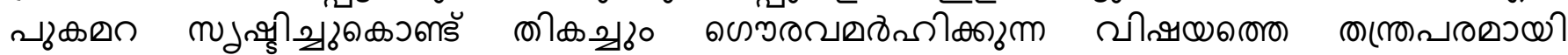

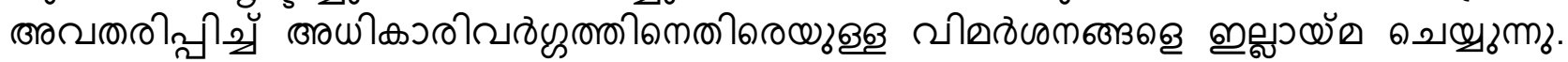

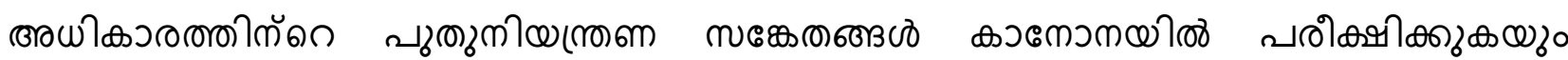
வ உழு

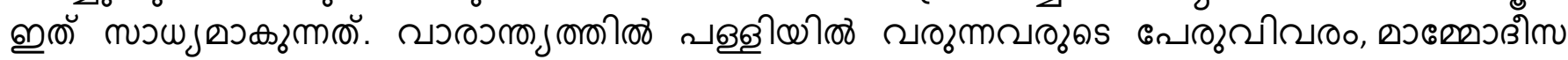

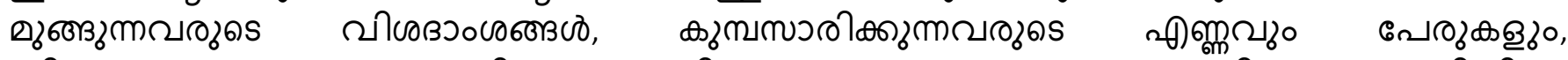

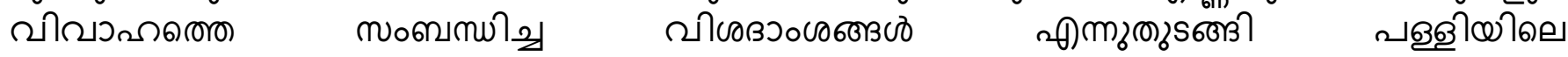

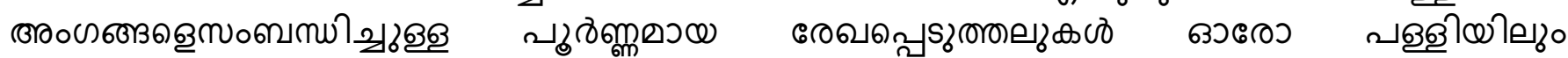

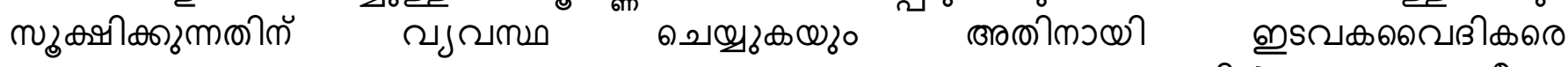

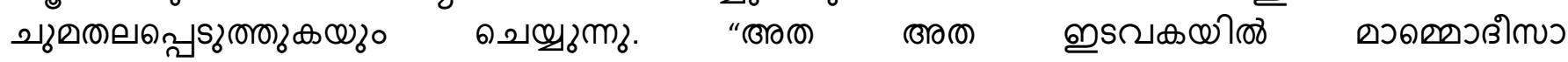

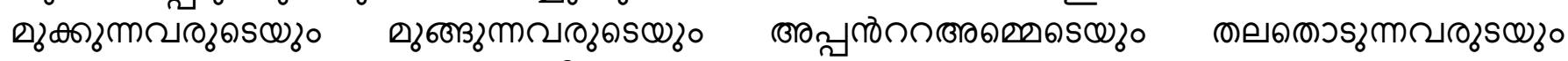

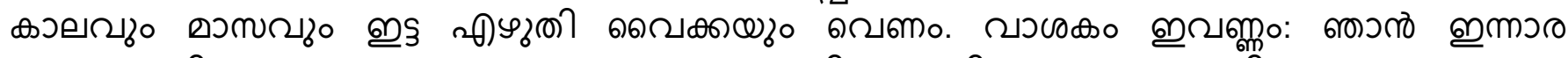

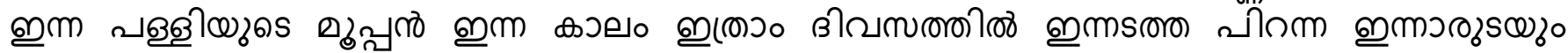

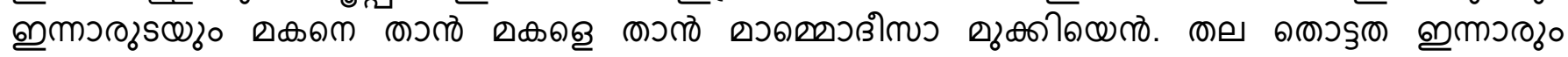

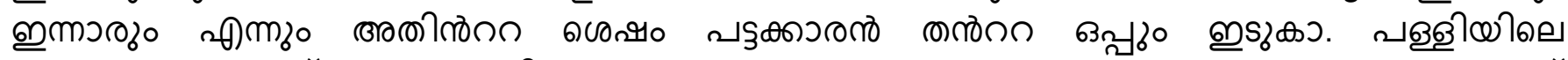

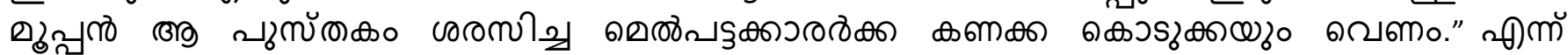

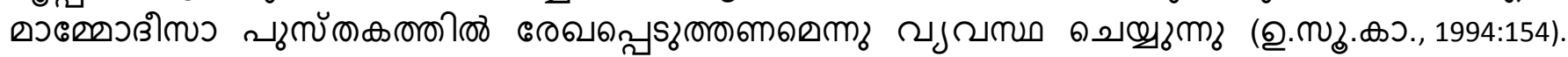

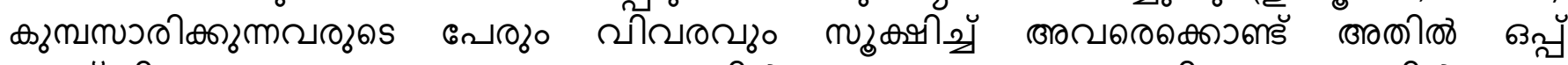

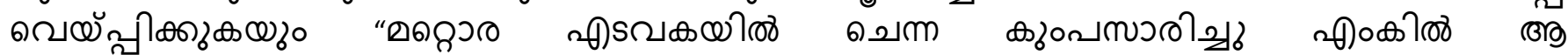

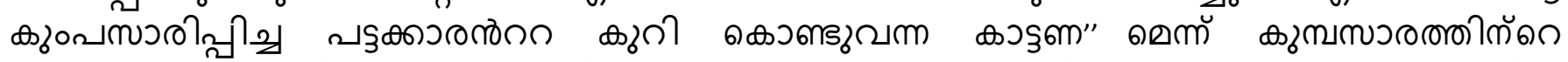

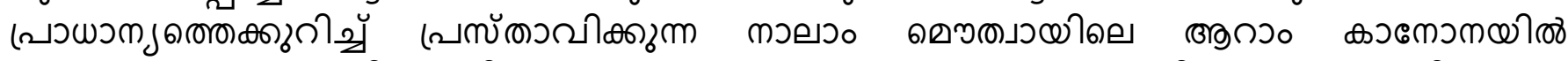

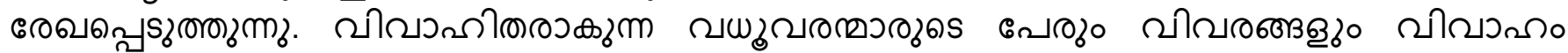

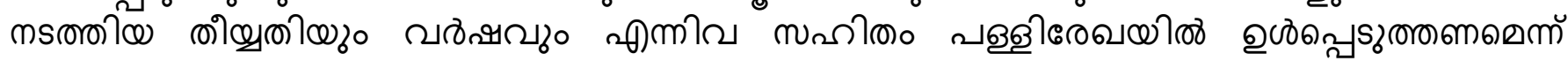

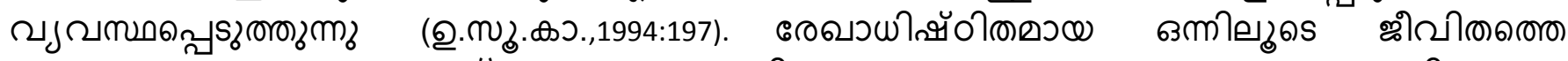

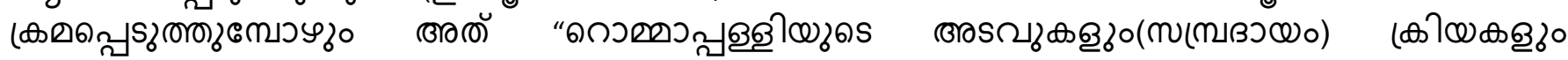

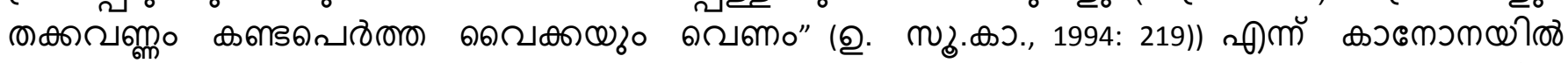

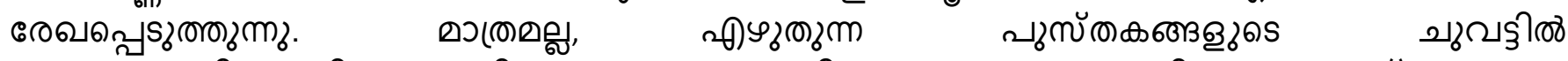

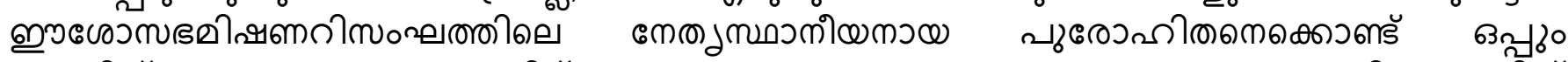

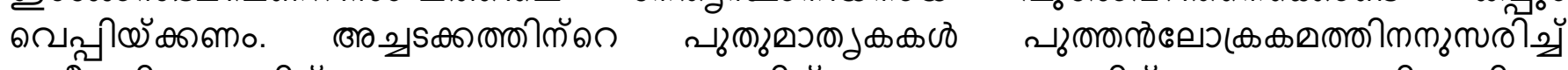

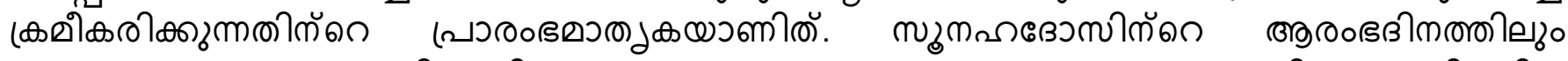

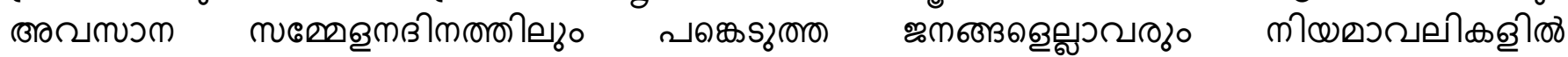

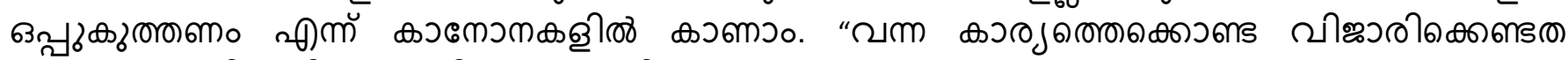

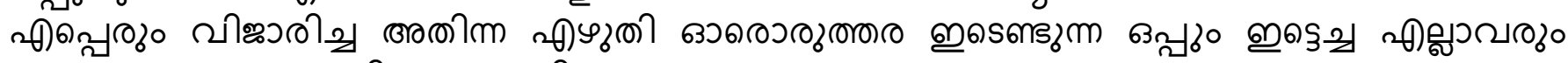

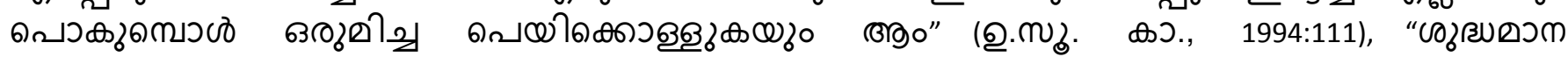

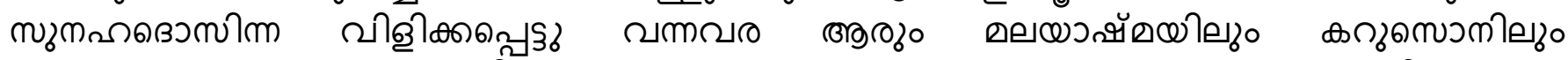

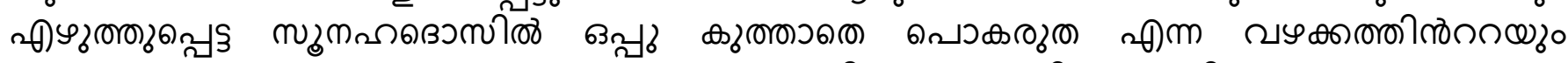

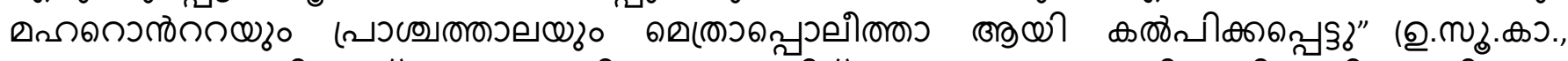

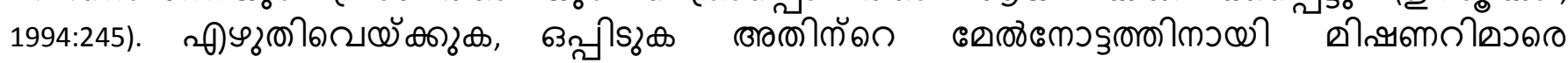




\section{Conflict of interest}

The Author has no conflicts of interest to declare that they are relevant to the content of this article.

\section{About the License}

(C) The author 2021. The text of this article is open access and licensed under a Creative Commons Attribution 4.0 International License

\section{Cite this Article}

Shimi Paul Baby, The Acts and Decrees of the Synod of Diamper and the Machinations of Religious Colonization, Indian Journal of Multilingual Research and Development, Vol 2, Iss 4 (2021) 53-60. DOI: https://doi.org/10.54392/ijmrd2147 